\title{
Fast Identification of Short Circuit Fault Based on Average Curvature of Current Waveform
}

\author{
Shaogui $\mathrm{Ai}^{1}$, Xiuming $\mathrm{Hu}^{2 . *}$, Yongning Huang ${ }^{3}$, Hui $\mathrm{Ni}^{3}$ and Zhiguo Hao ${ }^{2}$ \\ ${ }^{1}$ State Grid Ningxia Electric Power Company, Yinchuan 750001, China \\ ${ }^{2}$ Xi'an Jiaotong University, Xian 710049, China \\ ${ }^{3}$ Electric Power Research Institute of State Grid Ningxia Electric Power Company, Yinchuan 750001, China \\ ${ }^{*}$ Corresponding author
}

\begin{abstract}
Using fault current limiter (FCL) is an effective way to solve the problem that short circuit current exceeds the standard. How to quickly identify short circuit faults is one of the keys. Thus, this paper presented a fast identification method for short circuit fault based on the average curvature of current waveform. A simple fault current limiter system was built in PSCAD, and the method was studied. The results show that it is faster than using current instantaneous value or the current change rate as the criterion. In view of the situation that the average curvature may exceed when the load changes sharply. It was proposed that the average curvature and the current change rate could be used as the combination criterion, and the fault could be identified quickly and accurately too.
\end{abstract}

Keywords-fault current limiter; fast identification; short circuit Current; average curvature

\section{INTRODUCTION}

With the increasing electricity power load, the problem of excessive short circuit current is becoming more and more serious which becomes one of the major threats to the electricity power system [1]-[2]. By increasing the voltage level or the system impedance, there are technical barriers, extra expenses or will have a negative impact on the electricity system [3]-[4]. Using fault current limiter to solve this problem is an effective way [5]-[7].

To ensure the reliable input of short circuit current limiter, fast and accurate identification of short circuit fault is essential [8]. At present, numerous studies on this field have been carried out. According to the derivative information of the angular velocity and angular velocity of the generator, fuzzy judgment and reasoning can be used to identify the short circuit fault [9]. It is proposed that the instantaneous value of the line current, the line current differential and the line current integration can be the short circuit fault criterion [10]. In a short circuit current limiter project of East China Power Grid, the fault signal is quickly identified by the combination of the line current waveform slope and the instantaneous value [11].

Curvature is the amount that characterizes the trend. The curvature of current waveform has been used to identify the inrush current [12]. In this paper, it is proposed that the fault can quickly identified by using the average curvature of current waveform when load do not change sharply. We need to use both the average curvature and the current change rate in other situations. The simulation analysis was carried out, and the results show that the methods can meet the requirements of fastness and reliability at the same time.

\section{DEFINITION OF CURVATURE}

Curvature is the amount that characterizes the deviation of the curve from the straight line. As shown in Figure 1, for the plane curve $C$, with its point $M_{0}$ as a reference, the arc length is $\mathrm{s}$ from point $\mathrm{M}_{0}$ along the curve to point $\mathrm{M}$, and the arc length is $\Delta s$ from point $M$ to point $M^{\prime}$.The angle of rotation from point $\mathrm{M}$ to point $\mathrm{M}^{\prime}$ is $\Delta \alpha$.

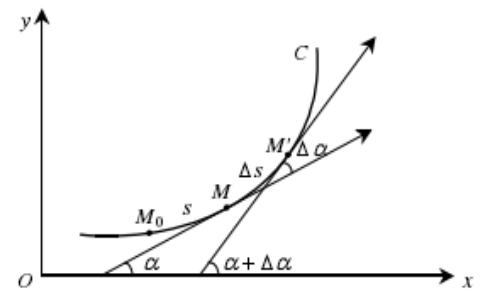

FIGURE I. CURVATURE DEFINITION OF PLANE CURVE

If $\Delta \mathrm{s} \rightarrow 0$, the ratio of $\Delta \alpha$ and $\Delta \mathrm{s}$ is the curvature of point $\mathrm{M}$, that is to say, the curvature of point $\mathrm{M}$ is $\Delta \mathrm{K}=\lim _{\Delta \mathrm{s} \rightarrow 0} \frac{\Delta \alpha}{\Delta \mathrm{s}}$. If the mathematical function of the curve is $y=f(x)$, the curvature of the point on it is $\Delta K=\frac{y^{\prime \prime}}{\left(1+y^{\prime 2}\right)^{\frac{3}{2}}}$, in

which $y^{\prime}$ and $y^{\prime \prime}$ is the first and the second derivative of the function.

\section{Application of CURRENT WAVEForm CURVATURE IN SHORT CIRCUIT FAULT IDENTIFICATION}

\section{A. The Basis of the Application}

When the electricity power system is running normally, there is almost no harmonic in the grid current. If only the fundamental frequency component is taken into account, the current-time curve expression can be described as $\mathrm{I}=\mathrm{A} \sin (\varpi \mathrm{t}+\theta)(\mathrm{A} \geq 0)$. The curvature of each point on the curve is: 


$$
\begin{gathered}
\Delta \mathrm{K}=\frac{-\mathrm{A} \varpi^{2} \sin (\varpi \mathrm{t}+\theta)}{\left[1+\mathrm{A}^{2} \varpi^{2} \cos ^{2}(\varpi \mathrm{t}+\theta)\right]^{\frac{3}{2}}} \\
-\mathrm{A} \varpi^{2} \leq \Delta \mathrm{K} \leq \mathrm{A} \varpi^{2}, 0 \leq|\Delta \mathrm{K}| \leq \mathrm{A} \varpi^{2}
\end{gathered}
$$

We can see that during time that the electricity power system is running normally, the curvature of each point on the current-time curve is within the closed interval between the maximum and the minimum. If a single threshold is set, it is possible to determine whether or not a short circuit fault has occurred based on whether or not the absolute value of the curvature is limited. The criterion is as follows:

$$
\left|K_{n}\right| \geq K_{\text {set }}
$$

In engineering practice, however, the current value is obtained by discretized sampling. The current-time curve depicted by the sampled data is no longer smooth and is not a true current-time continuous curve, so that the curvature of each point on the real curve can't be obtained. At this time, the average curvature can be used to describe the current change trend, the average curvature between the nth sample point and the $(\mathrm{n}+1)$ th sample point defined as $\mathrm{K}=\frac{\Delta \alpha}{\Delta \mathrm{s}}$. Where $\mathrm{K}$ can be positive or negative, $\Delta \alpha$ and $\Delta \mathrm{s}$ are given by:

$$
\begin{gathered}
\Delta \alpha=\arctan \frac{\mathrm{I}_{\mathrm{n}}-\mathrm{I}_{\mathrm{n}-1}}{\Delta \mathrm{t}}-\arctan \frac{\mathrm{I}_{\mathrm{n}+1^{-}-\mathrm{I}_{\mathrm{n}}}}{\Delta \mathrm{t}} . \\
\Delta \mathrm{s}=\frac{\sqrt{\left(\mathrm{I}_{\mathrm{n}}-\mathrm{I}_{\mathrm{n}-1}\right)^{2}+\Delta \mathrm{t}^{2}}+\sqrt{\left(\mathrm{I}_{\mathrm{n}+1}-\mathrm{I}_{\mathrm{n}}\right)^{2}+\Delta \mathrm{t}^{2}}}{2}
\end{gathered}
$$

Where $\Delta t$ is sampling step and $I_{n}$ is the current value of the nth sampling point. It is easy to see that when the sampling step is smaller, the average curvature is closer to the real curvature of the nth point. It should be noted that, due to the two different units of current and length of sampling step, units need to be converted before the calculation.

A simple power system is modeled to simulate a short circuit fault at 0.2 second, and the fault is identified by the average curvature between the sampling points, as shown in Figure 2.
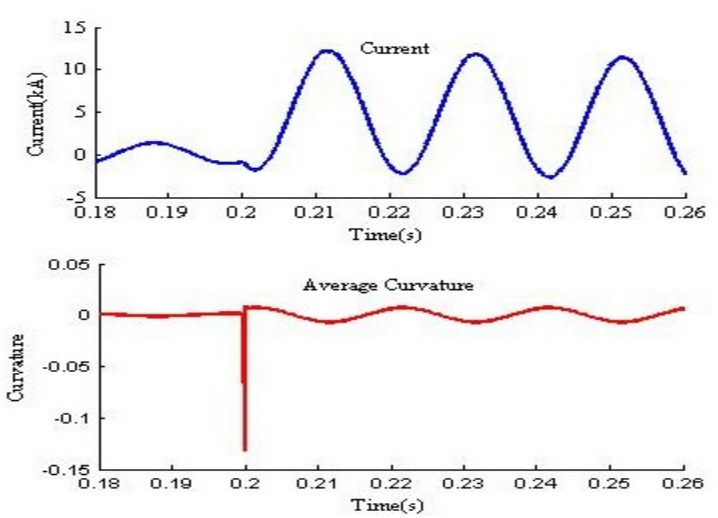

FIGURE II. FAULT IDENTIFICATION PRINCIPLE BASED ON AVERAGE CURVATURE OF CURRENT

The following conclusions can be drawn from the figure above:

a) When the electricity system is running normally, the average curvature of the current waveform changes within a small range. When the fault occurs, the average curvature suddenly increases or decreases beyond this range.

b) When short circuit fault occurs, the current value is greater than the normal, and the absolute value of the average curvature at the peak is also greater than the absolute value at normal.

\section{B. Feasibility Analysis and Improvement Measures}

The main advantage of fault identification with average curvature of current waveform is that when short circuit current change rate and the instantaneous value do not increased to a certain value, the fault can be determined and the recognition speed can be improved.

This advantage is determined by the curvature definition formula, the curvature formula used the second derivative, which also causes the disadvantage, that is sensitive to wave and interference. From Figure 2, we can see that the average curvature will be greater if the current value is greater. When current changes (increases or decreases) sharply, the average curvature of current waveform increases. A simple three-phase electricity system is modeled. The simulation system suddenly increases the load at $0.2 \mathrm{~s}$ and a ground fault occurs at $0.3 \mathrm{~s}$, the measured non-fault phase current and the average curvature of its waveform are shown in Figure 3.
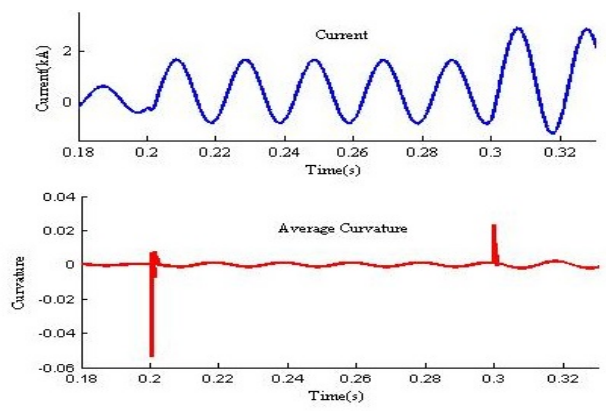

FIGURE III. THE NON - FAULT PHASE CURRENT AND AVERAGE CURVATURE OF ITS WAVEFORM 
At this time, only raising the setting value to distinguish normal operation can't be feasible because it will cause a failure to refuse act when real fault occurs.

Therefore, this paper is to propose that the average curvature of current waveform and current change rate can be used as a criterion to meet the requirements of fastness and reliability. The criterion is as follows:

$$
\left\{\begin{array}{l}
\left|\mathrm{K}_{\mathrm{n}}\right| \geq \mathrm{K}_{0 . \text { set }} \\
\left|\frac{\Delta \mathrm{I}_{\mathrm{n}}}{\Delta \mathrm{t}}\right| \geq \mathrm{K}_{1 . \text { set }}
\end{array}\right.
$$

In which, $\mathrm{K}_{0 \text {.set }}$ and $\mathrm{K}_{1 \text { set }}$ are the setting values of the average curvature and the rate of change.

\section{Simulation AND Verification}

In order to test identification capability based on the average curvature of the current waveform to short circuit fault, in PSCAD, a simple three-phase electricity power system is built. The system circuit is shown in Figure 4.

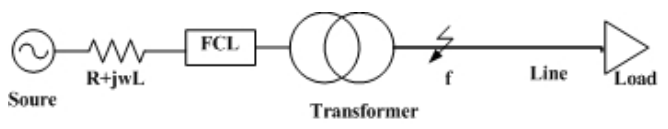

FIGURE IV. SIMPLE THREE-PHASE ELECTRICITY POWER SYSTEM

Based on this, the application of the average curvature of current waveform in short circuit fault identification is studied. The sampling step is 100us. To facilitate the calculation of the average curvature value, the sampling step 100us is counted as 1 and the current value $1 \mathrm{kA}$ is counted as 1 . If three-phase short circuit fault (the most serious case) occurred at $0.3000 \mathrm{~s}$. The fault point is located at the point $f$ at the low voltage side of the transformer. Taking the high-side a-phase winding current as an example, the current waveform and the mean curvature are shown below.

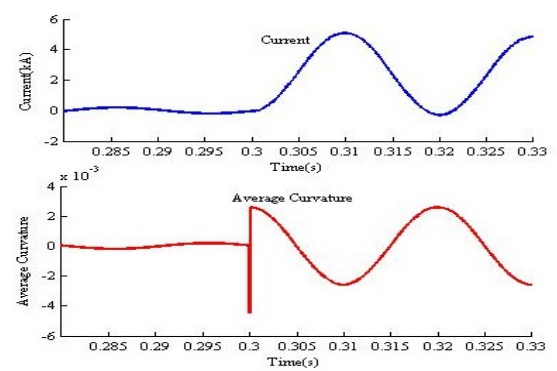

FIGURE V. A-PHASE CURRENT AND ITS AVERAGE CURVATURE

At normal operation, the maximum value of current instantaneous is $0.514 \mathrm{kA}$, the maximum current change rate is $0.161 \mathrm{kA} / \mathrm{ms}$, and the maximum average curvature is 0.0005066 . Considering the margin, we make the current instantaneous value, the rate of change, the average curvature as a criterion to identity the fault, the 3 setting values are $0.617 \mathrm{kA}, 0.193 \mathrm{kA} / \mathrm{ms}$, 0.000608 respectively. If the three-phase short circuit fault occurs at $0.3000 \mathrm{~s}, 0.3020 \mathrm{~s}, 0.3040 \mathrm{~s}, 0.3060 \mathrm{~s}, 0.3080 \mathrm{~s}$ and $0.3100 \mathrm{~s}$ respectively. The identification time of the three methods is as follows.

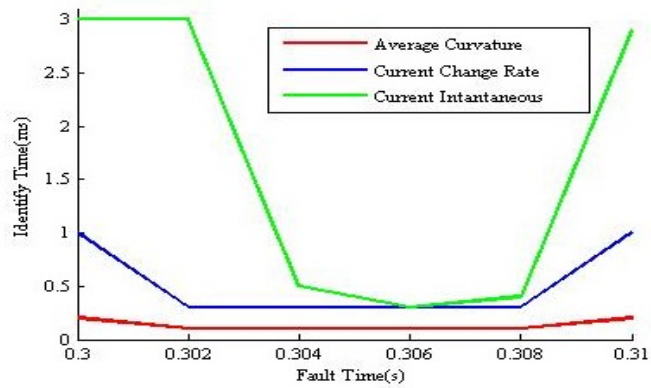

FIGURE VI. TIME COMPARISON BETWEEN THREE DIFFERENT IDENTIFICATION METHODS

From Figure 6, it can be seen that the time to identify faults based on the average curvature criterion is shorter and the identification speed is faster. At this time, the average curvature criterion can be used only to identify faults quickly and accurately. But in another case, this situation will change. At $0.2 \mathrm{~s}$, if the load suddenly decreases by $54.6 \%$ and recovered at $0.22 \mathrm{~s}$ (which is an extreme case), the fault still occurs at $0.3 \mathrm{~s}$, the current and the average curvature between $0.16 \mathrm{~s}$ and $0.34 \mathrm{~s}$ are shown in Figure 7.
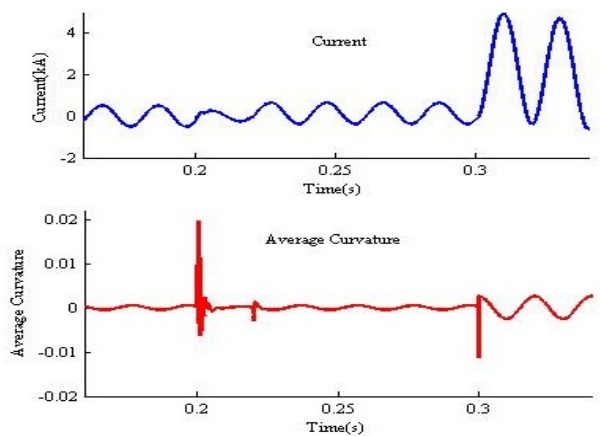

FIGURE VII. CURRENT AND AVERAGE CURVATURE WHEN LOAD DECREASE AND FAULT OCCURS

It is not difficult to see that the load suddenly decreases sharply at $0.2 \mathrm{~s}$, causing that the average curvature of current curvature increases abruptly, which exceeds the maximum average curvature after $0.3 \mathrm{~s}$. If a single average curvature criterion is used, there will be identification error. So, combination criteria need to be used. The current change rate is shown in Figure 8.

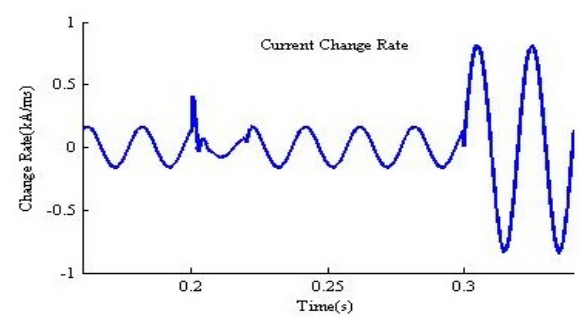

FIGURE VIII. CURRENT CHANGE RATE

The current change rate is much greater near at $0.3 \mathrm{~s}$ than near at $0.2 \mathrm{~s}$ which maximum is $0.411 \mathrm{kA} / \mathrm{ms}$. Based on this, we propose that the average curvature of current waveform and current change rate can be used as a combination criterion to 
identity short circuit fault. To ensure the rapidity of identification at the same time, the setting values in combination criterion should be smaller than the value of the single criterion. In the above situation, we make the setting value of average curvature 0.000557 and the setting value of current change rate $0.411 \mathrm{kA} / \mathrm{ms}$. The identify time using the combination criterion is longer than usual only using average curvature as criterion, but is more accurate. When only using current change rate, the setting value should be $0.4932 \mathrm{kA} / \mathrm{ms}$. The identify time of the two criterions is shown in Figure 9.

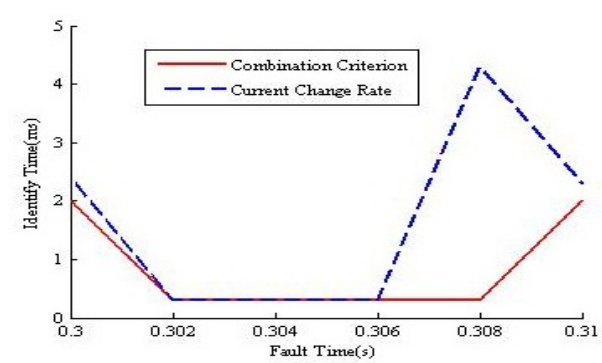

\section{FIGURE IX. IDENTIFY TIME OF TWO DIFFERENT CRITERIONS}

It can be seen that the identification time using the combination criterion is less than or equal to the identification time using the rate of change criterion when faults occur at different time.

\section{CONCLUSION}

In this paper, a method based on the average curvature of current waveform to identify short circuit fault was developed. After principle analysis, simulation has been carried out. Using the average curvature of current waveform as criterion, fault could be identified more quickly and accurate than using current change rate or instantaneous value if there was not sharp load change. Combination criterion both using the average curvature and current change rate should be used in other situations. But it also showed the speed was faster than the simple rate criterion.

\section{REFERENCES}

[1] N. R. L. Sirisha; Ashok Kumar Pradhan. "Parameter Estimation of Resonant Fault Current Limiter for Protection and Stability Analysis,” IEEE Transactions on Power Systems, vol. 32, no. 3, pp. 2288 - 2295, 2017.

[2] B. Raju, K. Parton, and T. Bartram, "A current limiting device using superconduction DC bias applications and prospects," IEEE Trans. Power App. Syst., vol. PAS-101, no. 9, pp. 3173-3177, Sep. 1982.

[3] S. Abbott, D. Robinson, S. Perera, F. Darmann, C. Hawley, and T.Beales, "Simulation of HTS saturable core-type FCLs for MV distribution systems," IEEE Trans. Power Del., vol. 21, no. 2, pp. 1013-1018, Apr. 2006.

[4] L. Salasoo et al, "Comparison of superconducting fault current limiter concepts in electric utility applications," IEEE Trans. Appl. Superconduct, vol. 5, no. 2, pp. 1079-1082, Jun. 1995.

[5] Abbas Esmaeili, Saeid Esmaeili, Hossein Hojabri, "Short-circuit level control through a multi-objective feeder reconfiguration using fault current limiters in the presence of distributed generations," IET Generation, Transmission \& Distribution, vol. 10, no. 14, pp. 3458-3469, 2016.

[6] Morandi, A, "State of the art of superconducting fault current limiters andtheir application to the electric power system," Phys. C, Supercond, no 484, pp. 242-247, 2013
[7] Abramovitz, A, Smedley, K.M, "Survey of solid-state fault current limiters,” IEEE Trans. Power Electron, vol. 27, no.6, pp. 2770-2782, 2012.

[8] Hamid Jafarabadi Ashtiani; Haidar Samet; Teymoor Ghanbari, "Evaluation of directional relay algorithms in the presence of FCL," IET Science, Measurement \& Technology, vol. 11, no. 6, pp. 713-722, 2017.

[9] Yuan Qing-fang, Li Xing-yuan, "Fuzzy stable controller of a fault current limiter with series compensation," Automation of Electric Power Systems, Vol. 28, no. 3, pp. 24-27, Feb. 2004.

[10] Yang Da’ou, Luo Ping, Yao Huiran, "Research on new type short circuit current limiter utilizing LC harmonic oscillation,” Northeast Power Syste Technology, vol. 21,no. 9, pp. 28-31, 2000.

[11] Ming Zhao, "Principle of power network short circuit protection based on current change rate,” Power System Technology, vol. 32, no. 4, pp. 105-108, Feb. 2008.

[12] Xuefen Jin, Chaobo Dai, Shouyuan Wu, Ping Jing, "Fast Fault Signal Identification Method Using Line Current Slope,” Power System Technology, vol. 33, no. 9, pp. 30-34, May. 2009. 